\title{
Rural architecture, tourism and simulacra
}

\author{
J. Theodoraki-Patsi \\ National Technical University Athens, Greece
}

\begin{abstract}
The intersections between traditional and modern culture and the current the "network society" produce hybrids and heterogeneity. What will eventually survive defines the prospect of architectural evolution and architectural heritage to ensuing generations. Greek rural architecture presents architectural elements distinct even between neighboring settlements documenting the evolution of the phenomenon.

Heterogeneity reflects diversity that exists in time and space and demands respect from current culture and values. Contemporary Greek culture is rooted and continues to elaborate the cultural intersection between East and West. The diversity of architectural heritage in settlements created before 1923 (chronology of the constitution of the contemporary Greek territory) is an irreplaceable source of spiritual and intellectual richness for study. In every micro-region is recorded a spectacular variety of rural architectural elements originated from a specific historical period and culture. Indeed in most cases, where due to a crisis (earthquake or other) the interval of history is clearly perceived, there is visible appearance of the diverse phases of heterogeneity and hybrids survival.

Architectural heritage is constructed in historical periods of the past and as it was decided, it should be conserved by virtue of a particular legislative framework implemented in Europe since 1985 and applied by Public authorities. Some architectural representations with a particular beginning, duration and end (such as neo-classicism) constitute architectural heritage and are consequently governed by the legislation of architectural heritage conservation.

Nonetheless, (re)constructions and neo-traditional representations - just for tourism consumption - do not constitute architectural heritage but an image making, a new simulacrum. For now simulacra deconstructs the intentions of the in-set culture (tourism) in rural areas and in this sense reflects the defense of a society to an invasion. The hybrids and what will evolve in future time perhaps will constitute architectural heritage. In the etymological sense of architectural heritage, however, the representations and (re)constructions - with all the deconstructing hybridity - are an architectural product that will be transferred to the coming generations and their duration and end are to determine whether they will be fertile or sterile chapters of the history of architecture.
\end{abstract}

Keywords: simulacra, hybridity, representation, tourism. 


\section{Dichotomies of the built environment}

Irrespective of historical courses and local individuality, in recent centuries the evolution of every society has followed similar intellectual dichotomies [1], which were represented congenially within the built environment. The above dichotomies continue to be specified nowadays with the progression of modern information technology [2].

- the rural/urban and

- the local/global

However today, a novel dichotomy emerges between the users of "globalization through the instant communication of information technology" and the receivers of "domestic individuality" [3].

The "users" are seeking the "receivers" as recourse for their reclusion and the latter utilize their rural and consequently local individuality, as an endogenous dynamic for tourism attraction.

In the context of this evolution the topic of rural architecture acquires a twofold meaning:

- As an endogenous dynamic for development: tourism (for commodities intended for use)(fig. 1).

- As an architectural representation (as itself a simulacra) of a traditional space for recreation. It means a set of practices, normally governed by a ritual or symbolic nature, which seek to inculcate certain values and norms by reputation, which automatically implies continuity with the past (fig.2).

The accent on local architecture also is generated by the historical interconnection of the agrarian-industrial-urban society or as it is today determined agrarian-industrial-informational society [4].

As the new arrangement of informational society occurs in a virtual level what has been already built is suitable for the new era as well (earth becomes

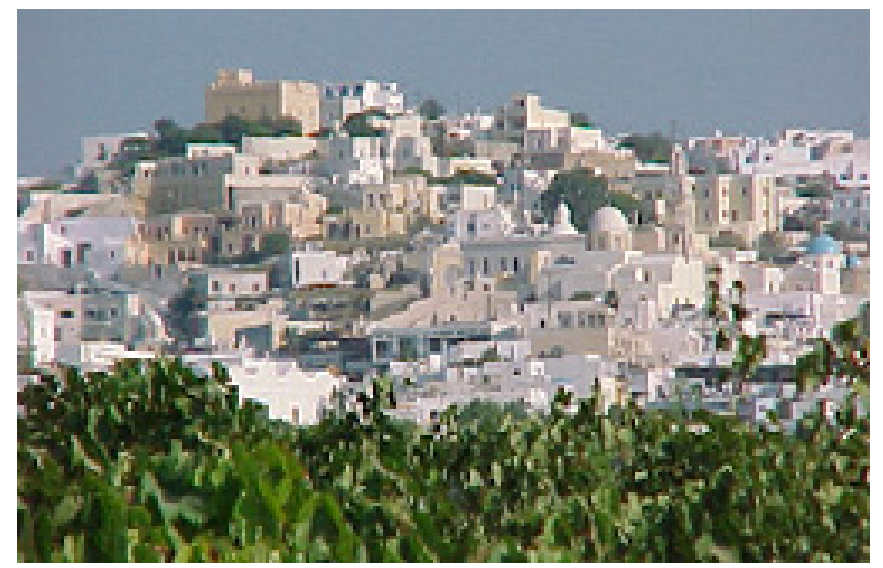

Figure 1: Housing in Fira, Santorini Island. 


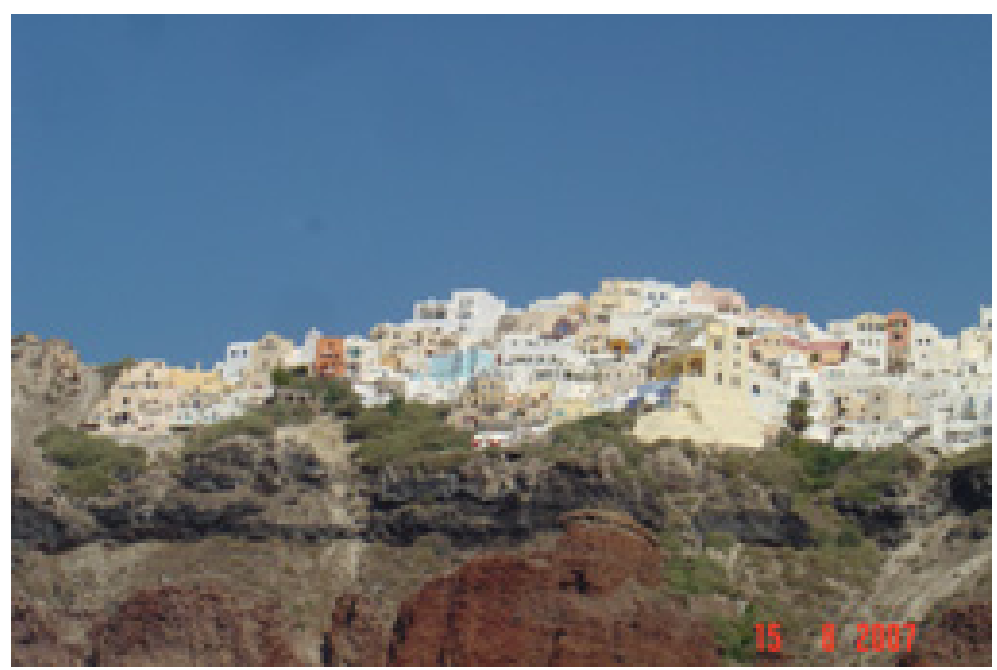

Figure 2: (Re)construction of "traditional" space in Ia, Santorini Island.

placeless), as though there occurs a convocation of the historical evolution and the technological change. At this point every culture is suitable for the informational society and even it is possible the "reset" of a culture outside the place that produced it.

Is it that "traditional" architecture (with its twofold nature: endogenous dynamic and traditional representation) functions as an antidote to virtual reality? Is it a general schema of hybridization of thought and action? Or is it simply the wrapping of some nostalgia induced by inertia at critical [5] times, until a new organization of the built environment, currently invisible, arises?

The intersection of cultures and hybrids becomes unpredictable, resulting in a pluralistic heterogeneity, declaring the end of all systems of meaning. It creates a mixture of elements (fig. 3) that searches formal harmony out of trans-historical and stylistic provocation with the purpose to make commonplaceness disappear [6].

The architectural identity is defined by virtue of individuality and a series of qualities related to uniqueness, differentiation, functionality and cohesion of a form of structure. The logic of architectural identity is established within the framework of the evolutionary theory [7] and follows its methodology that classifies built form according to geographical units, in order to distinguish the typological differences. The word classification suggests the arrangement of objects under congenial categories and it is the law of the evolutionary process in biology conveyed in architecture [8].

\section{Representation in Greece}

The restructuring of the Greek country followed different phases according to the addition of successive regions that had been under distinct occupation for 


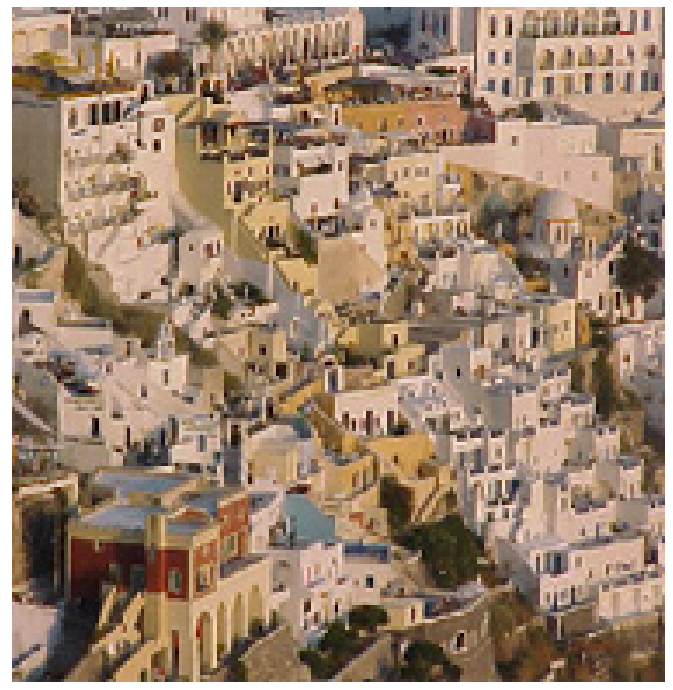

Figure 3: $\quad$ Mixture of elements and simulacra in Fira, Santorini Island.

centuries. In the early $19^{\text {th }}$ century Greece comprehended Peloponissos and Sterea, which had been under the Turk occupation since the $15^{\text {th }}$ century. In the early $19^{\text {th }}$ century, parts of Greece such as the Ionian Islands and Crete - which had been under Latin occupation until then - were turned under Turkish control until their later liberation. Northern and Eastern Greece (Epirus, Macedonia, Thraki and most of the islands of Aegean sea) continued to be under Turkish occupation and were liberated by turns during the $20^{\text {th }}$ century. Population movements and intercrosses between cultures provided a variety of architectural elements distinct even in neighboring settlements which corresponds to the architectural heritage of each micro-region that the modern Greek state inherited.

European romanticism of the $18^{\text {th }}$ century and consequently the development of neoclassical patterns for the built environment while a representation for the nations of the West, for Greece - the land where ruins of classical values were still present - were incorporated in the ideology of the new nation and functioned as part of the domestic evolution. In fact the clear distinction in Greece can only be perceived in the distribution of plots and plans, while in three dimensions neoclassicism is fused with traditional patterns.

From the mid $20^{\text {th }}$ century modern architectural movement, once more inspired from simple cubic forms of Aegean sea islands architecture, intercrossed with previous traditional and neoclassical architecture composed the contemporary Greek architecture that continuous to evolve and to be context specific.

In fact in Greece the since $19^{\text {th }}$ century perceptions and attitudes have been expressed in the architecture of the built environment giving rise sequentially to architectural patterns - Neoclassicism (fig 4), Local identity (fig. 5), Modern (fig. 6) - and the implicit hybrids. 


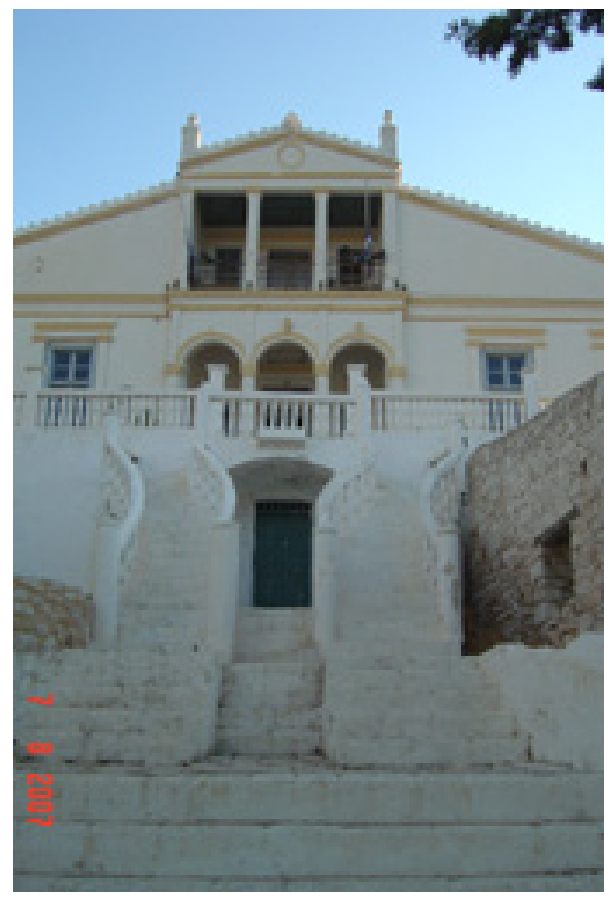

Figure 4: Neoclassicism in Chalki Island.

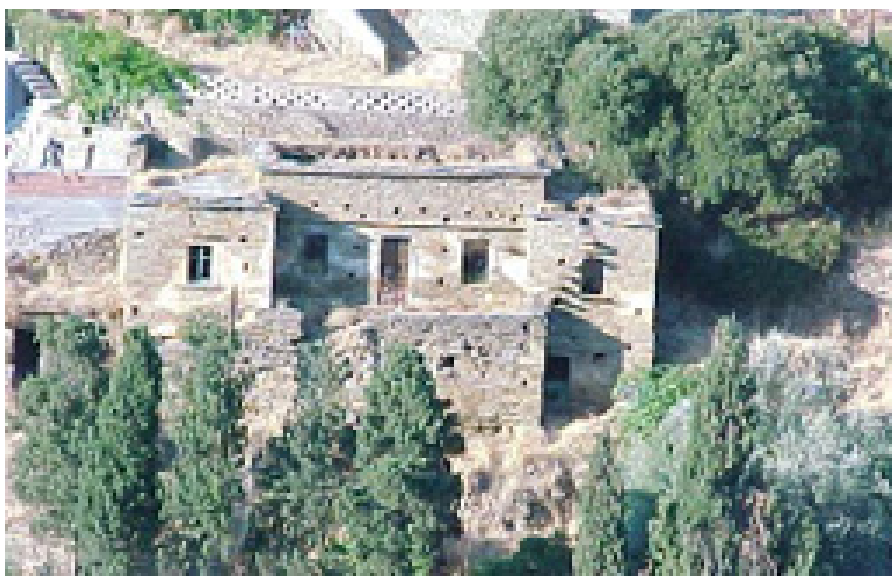

Figure 5: Local identity in Andros Island. 


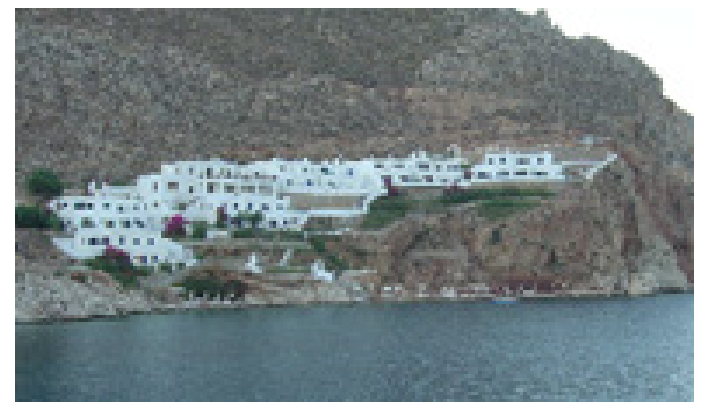

Figure 6: Authenticity in Tilos Island.

\section{Current era}

The intersection between opposite cognitive systems and now the network society in the context of a continual influx of information activates new hybridity due to the heterogeneity involved. What will eventually survive defines the prospect of architectural evolution and architectural heritage to ensuing generations. Greek architecture presents architectural elements distinct even between neighbor settlements documenting representations with an equivalent image between sign and reality.

Heterogeneity embodies diversity that exists in time and space and demands respect from current cultures and values. Contemporary Greek culture is rooted and continues to elaborate the cultural intersection between East and West. The diversity of architectural heritage in settlements created before 1923 (chronology of the constitution of the contemporary Greek territory) is an irreplaceable source of spiritual and intellectual richness for study. In every micro-region is recorded a spectacular variety of architectural elements originated from a specific historical period and culture (figs. 7,8). In most cases indeed, where due to a crisis (earthquake or other) the interval of history is clearly perceived and there is visible appearance of the diverse phases of heterogeneity and hybrids survival.

The antithesis of the two cognitive systems in the current post-global age, continues to be evident producing simulacra [9] (fig. 9) beyond control, which deconstructs every significance. In other words, the difficulty of "place making with a local individuality" is becoming more intense, as there is notable discord between "western linear" and "anthropological concentric logic" and their coexistence leads to heterogeneous phenomena and brings about confusion.

Efforts are being made to use historic forms in order to achieve "a representation of the character of each place". It seems however that to a larger extent than historic forms it is the people who define place and the consequent individual atmosphere, the people who inhabit the place and perform a number of activities there. This last fact contributes to preserving traditional uses [10] and activities in new structures (fig. 10). 


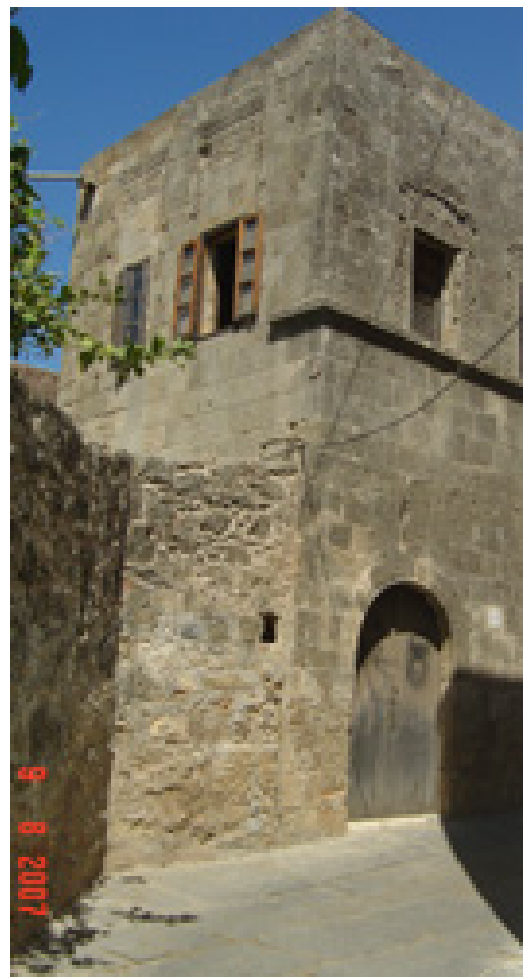

Figure 7: $\quad$ Lindos, Rhodes island.

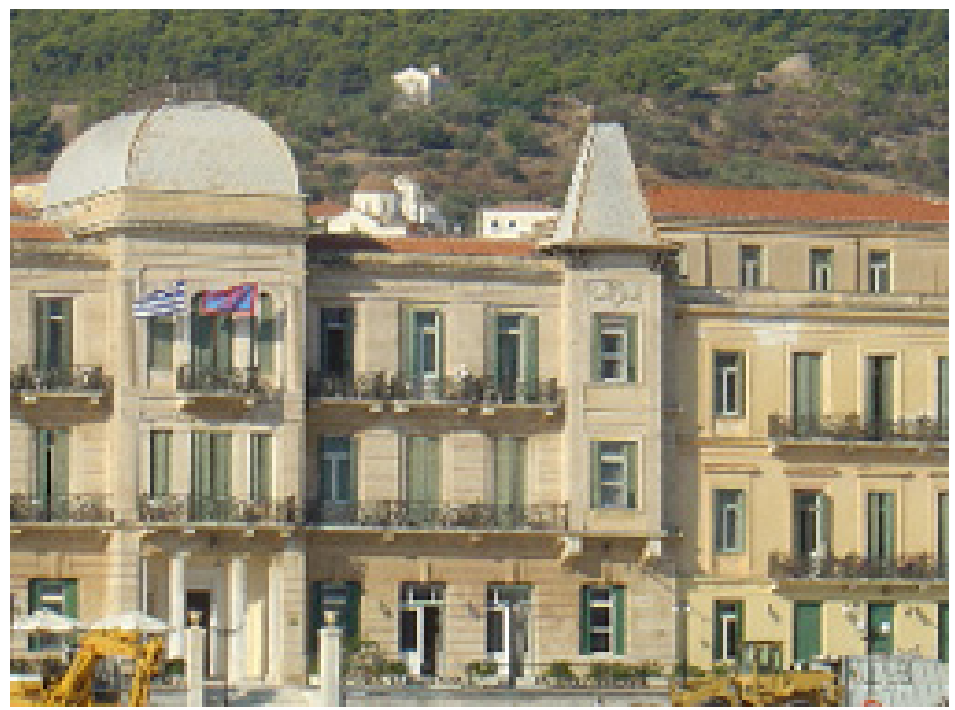

Figure 8: $\quad$ Spetses Island. 


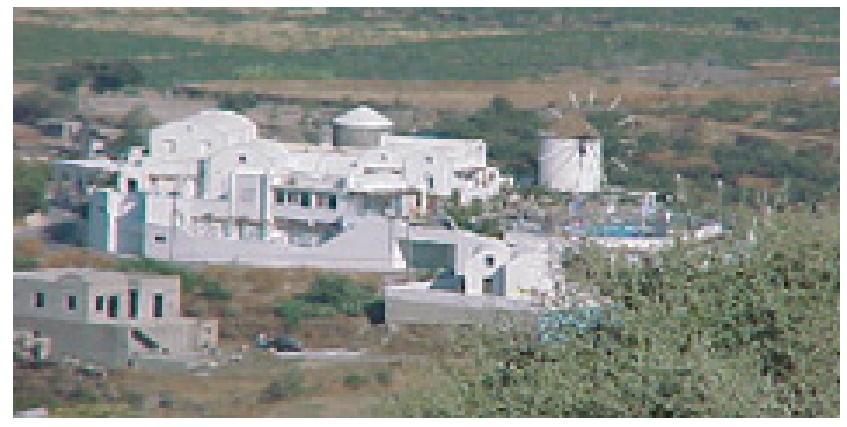

Figure 9: $\quad$ Simulacra in Santorini Island.

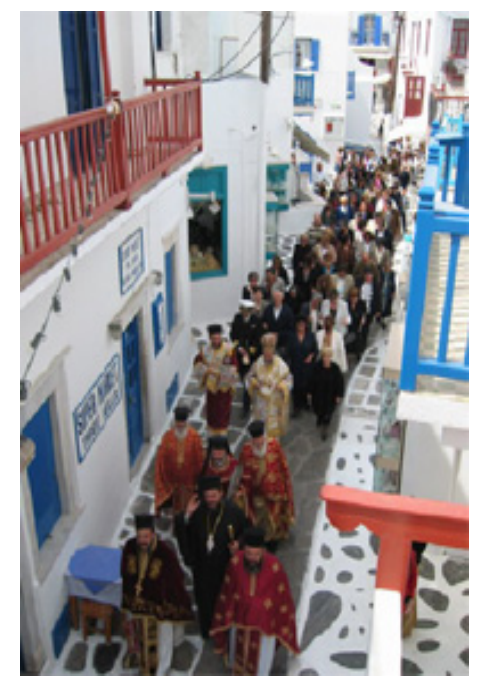

Figure 10: Activities that contribute to the individual atmosphere of a place and attract tourism.

\section{Conclusion}

Simulacra are copies of things that no longer have an original use. In these sense any architectural representation can be included in this term. During the last century in Greece architecture has evolved through systematic neo-classical representation on the one hand and with the use of traditional architectural elements on the other. In the same period that other countries had to incorporate neoclassicism and later on the modern movement (as international styles) Greek architecture had continuity for both. Greek traditional architecture served as well as a prototype - with the simple and cubist forms of Aegean Sea architecture for the masters of the modern movement. The question that remains is about the novel dichotomy between the "users" of the instant communication (product of 
western rational thinking) and the "receivers" of local cultures, injecting information into contradictory contexts, once inaccessible, and transforming local individualities in theme parks [11] and finally wrapping with some nostalgia the paradox "instant" amusement of contemporary tourism. Tourism by it self as an experience expect staged authenticity but also a "true" authenticity to exist. The last introduces local traditional architecture as the "true" authenticity that "wraps" the package.

The general conclusion of the synthesis of the terms "rural architecture tourism and simulacra" is that rural individuality produced a renaissance on tourism with the build environment playing a central role. Individuality is the product of the senses of a place, the identity and the evolution of the built environment that the global pressure of tourism reduce to simulacra when and where profit does not allow the time for authentic evolution. Nowadays important research on environmental perception, tourist image, destination image, motivation, and decision making is contributing to the science of epistemology in order to assess the most appropriate theories about tourist experience, which after all depends on the inadequacies of human perception.

\section{References}

[1] P. Cloke \& R. Johnston, Spaces of geographical though, Sage, 2005.

[2] P. Virilio, Open Sky, Paris, Verso, 1997.

[3] M. Castells, The rise of the Network society, Oxford, Blackwell, 2000

[4] http://hjem.get2net.dk/gronlund/Castells.html: Bo Gronlund, M. Castells confronted, p.7.

[5] M. De Landa, A thousand years of non-linear history, London, Swerde, 2000.

[6] D. Boorstin, The Image, pp. 77-117, Vintage, N. York, 1987

[7] P. Oliver, Enc. of vernacular architecture of the world, vol. I, p.36, Cambridge, Cambridge Univ. Press, 1998.

[8] There is an abundant use of references on metaphors taken from molecular biology and spread among architects, A. Picon, «Architecture, science, technology and the virtual realm» in A. Picon \& A. Ponke, Architecture and the sciences, p. 293, Princeton Architectural Press, 2000.

[9] J. Baudrillard, Simulations, Semiotext(e), Inc., Columbia University, N. York, 1983.

[10] T. Mitchell, "The invention and reinvention of the peasant" in Rule of experts, p.p. 123-152,California University Press, 1955.

[11] M. Sorkin (ed.), Variations on a theme park, Hill \& Wang, N. York, 1992. 